\title{
RESEARCH
}

\section{Functional significance of germline EPAS1 variants}

\author{
Trisha Dwight $\mathbb{D}^{1,2, *}$, Edward Kim1,2,*, Karine Bastard1,2, Diana E Benn1,2, Graeme Eisenhofer3,4, Susan Richter3, \\ Massimo Mannelli5 ${ }^{5}$ Elena Rapizzi ${ }^{5}$, Aleksander Prejbisz ${ }^{6}$, Mariola Pęczkowska6 ${ }^{6}$ Karel Pacak and \\ Roderick Clifton-Bligh 1 1,2,8
}

${ }^{1}$ Cancer Genetics Laboratory, Kolling Institute, Royal North Shore Hospital, St Leonards, New South Wales, Australia 2University of Sydney, Sydney, New South Wales, Australia

3Institute of Clinical Chemistry and Laboratory Medicine, University Hospital Carl Gustav Carus, Technische Universität Dresden, Dresden, Germany ${ }^{4}$ Department of Medicine III, University Hospital Carl Gustav Carus, Technische Universität Dresden, Dresden, Germany

${ }^{5}$ Department of Experimental and Clinical Medicine, University of Florence, Florence, Italy

${ }^{6}$ Department of Hypertension, National Institute of Cardiology, Warsaw, Poland

${ }^{7}$ National Institutes of Health, Bethesda, Maryland, USA

${ }^{8}$ Department of Endocrinology, Royal North Shore Hospital, St Leonards, New South Wales, Australia

Correspondence should be addressed to R Clifton-Bligh: roderick.cliftonbligh@sydney.edu.au

*(T Dwight and E Kim contributed equally to this work)

\begin{abstract}
Mosaic or somatic EPAS1 mutations are associated with a range of phenotypes including pheochromocytoma and/or paraganglioma (PPGL), polycythemia and somatostatinoma. The pathogenic potential of germline EPAS1 variants however is not well understood. We report a number of germline EPAS1 variants occurring in patients with PPGL, including a novel variant c.739C >A (p.Arg247Ser); a previously described variant c.1121T>A (p.Phe374Tyr); several rare variants, c.581A>G (p.His194Arg), c.2353C>A (p.Pro785Thr) and c.2365A>G (p.Ile789Val); a common variant c.2296A>C (p.Thr766Pro). We performed detailed functional studies to understand their pathogenic role in PPGL. In transient transfection studies, EPAS1/HIF-2 $\alpha$ p.Arg247Ser, p.Phe374Tyr and p.Pro785Thr were all stable in normoxia. In co-immunoprecipitation assays, only the novel variant p.Arg247Ser showed diminished interaction with PVHL. A direct interaction between HIF-2 $\alpha$ Arg247 and PVHL was confirmed in structural models. Transactivation was assessed by means of a HRE-containing reporter gene in transiently transfected cells, and significantly higher reporter activity was only observed with EPAS1/HIF-2 $\alpha$ p.Phe374Tyr and p.Pro785Thr. In conclusion, three germline EPAS1 variants (c.739C >A (p.Arg247Ser), c.1121T>A (p.Phe374Tyr) and c.2353C $>$ A (p.Pro785Thr)) all have some functional features in common with somatic activating mutations. Our findings suggest that these three germline variants are hypermorphic alleles that may act as modifiers to the expression of PPGLs.
\end{abstract}
Key Words
- pheochromocytoma
- paraganglioma
- hypoxia- inducible factors
- EPAS1
- HIF-2 $\alpha$
$\checkmark \mathrm{VHL}$

\section{Introduction}

Cells sense and respond to low oxygen conditions in large part via hypoxia-inducible factor (HIF)-mediated transcription (Kaelin et al. 2016). In normoxia, HIF- $\alpha$ is hydroxylated by oxygen-dependent prolyl hydroxylases (PHDs) then ubiquitinated by pVHL-E3 ligase for proteasomal degradation (Maxwell et al. 1999, Hon et al.
C 2021 The authors Published by Bioscientifica Ltd. Printed in Great Britain

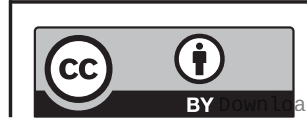

This work is licensed under a Creative Commons Attribution 4.0 International License.
Endocrine-Related Cancer (2020) 28, 97-109 
2002). In hypoxia, PHDs are inactive leading to HIF- $\alpha$ stabilization and transactivation of hypoxia-responsive genes, typically via heterodimers with HIF- $\beta$ also known as aryl hydrocarbon receptor nuclear translocator (ARNT) (Dengler et al. 2014). Two HIF- $\alpha$ isoforms, HIF-1 $\alpha$ and HIF- $2 \alpha$ have a high sequence homology encoding for two oxygen-dependent degradation domains, as well as two transactivation domains (Erbel et al. 2003, Schödel et al. 2011). Although they share common target genes, studies have shown that regulation and function of these proteins differ in tumor cells (Loboda et al. 2010, Qin et al. 2014). Their transcriptional responses include genes associated with angiogenesis, proliferation, anaerobic metabolism and resistance to apoptosis. As these biological consequences align with canonical hallmarks of cancer, numerous studies have reported that tumorigenesis is frequently accompanied by illegitimate activation of hypoxia responses at normal oxygen levels ('pseudohypoxia', or the Warburg effect) (Warburg 1956, Ruan et al. 2009).

Pheochromocytomas and paragangliomas (PPGLs) are tumors of the adrenal medulla and autonomic ganglia, respectively, that often demonstrate this HIFdependent pseudohypoxic switch of energy metabolism, in particular when associated with specific hereditary syndromes including Von Hippel-Lindau (VHL), SDHA, SDHB, SDHC, SDHD, SDHAF2, Egl nine homolog 1 (EGLN1/ PHD2), EGLN2(PHD1), malate dehydrogenase 2 (MDH2), and fumarate hydratase (FH) (Dahia et al. 2005, Robledo et al. 2017). A direct role for HIF- $2 \alpha$ in the pathogenesis of PPGL was first suggested by Zhuang et al. in 2012 when somatic gain-of-function variants were identified in patients with PPGL, somatostatinoma and polycythemia. Now termed the Pacak-Zhuang syndrome, these EPAS1 variants cluster around proline 531, one of two HIF- $2 \alpha$ hydroxylation residues. Functional studies have shown that these EPAS1 mutants are not fully hydroxylated by PHD2 and are stable in normoxia (Pacak et al. 2013, Yang et al. 2013, Jochmanova \& Lazurova 2014). These EPAS1 variants are exclusively somatic or mosaic (Favier et al. 2012, Buffet et al. 2014, Crona et al. 2014, CominoMéndez et al. 2013, Yang et al. 2015). There have been few case reports of PPGL- associated with the germline EPAS1 variant c.1121T>A, p.(Phe374Tyr) (Lorenzo et al. 2013, Welander et al. 2014, Taïeb et al. 2016) but the pathogenicity of that variant remains controversial.

We report the occurrence of several germline EPAS1 variants in patients with PPGLs, and performed detailed functional studies to validate the clinical significance of this observation. We report three germline EPAS1 variants
(c.739C>A (p.Arg247Ser), c.1121T>A (p.Phe374Tyr) and c.2353C $>$ A (p.Pro785Thr)) all have functional features in common with the well-known activating mutation p.Pro531Thr. Our findings suggest that these three germline variants are hypermorphic alleles that may act as modifiers to the expression of PPGLs.

\section{Materials and methods}

\section{Patient cohort}

DNA was extracted or provided from peripheral blood leukocytes of 300 individuals with PPGL (Australian $(n=133)$, German $(n=45)$, Italian $(n=52)$ and Polish $(n=70))$. The Australian cohort was sequenced as part of validation for next-generation sequencing, and most samples were de-identified for this purpose without access to corresponding clinical data; two subjects previously enrolled in the Australian SDH Consortium provided written informed consent for use of their de-identified clinical details (Northern Sydney Local Health District Human Research Ethics Committee, Kolling Neuroendocrine Tumour Bank Protocol \#11011$361 \mathrm{M}$ and Australian SDH Consortium Protocol \#1103$101 \mathrm{M})$.

\section{Sequencing}

Sequencing was performed as previously described (Dwight et al. 2016) using a custom gene panel (TruSeq ${ }^{\circledR}$ Custom Amplicon Assay, Illumina) encompassing the protein-coding and flanking intronic regions of EPAS1 (NM_001430.5, NP_001421.2). Briefly, DNA libraries were prepared (using $250 \mathrm{ng}$ of DNA from each sample) and sequenced on a MiSeq platform (using $2 \times 150$ bp paired end reads) according to the manufacturer's instructions (Illumina). FASTQ files (containing reads and their base call quality scores) were generated for each sample; alignment of reads (banded Smith-Waterman algorithm) and variant calling (GATK (Lin et al. 2011)) was processed by MiSeq Reporter (version 2.0, Illumina). Annotation of functional consequences to variant calls was performed using ANNOVAR (version $2013 \mathrm{Jul}$ (Liu et al. 2007)), which incorporates various in silico tools, including (but not limited to) PolyPhen-2, SIFT, MutationTaster. Visualization of reads was performed using IGV (v2.1). All EPAS1 variants were confirmed on Sanger sequencing. (c) 2021 The authors Published by Bioscientifica Ltd. Printed in Great Britain
This work is licensed under a Creative Commons Attribution 4.0 International License. ded from Bioscientifica.com at 04/26/2023 06:41:32AM via free access 


\section{Penetrance and confidence interval calculation}

Bayesian calculation of the conditional probability of disease (penetrance) given the genotype was performed using methods as previously described (Minikel et al. 2016, Benn et al. 2018).

\section{Plasmid and site-directed mutagenesis}

Plasmid pCMV6-EPAS1-GFP (RG208604, Origene) was used as the template for site-directed mutagenesis (QuikChange Lightning Site-Directed Mutagenesis Kit, Agilent) to produce EPAS1 variants c.581A $>\mathrm{G}$ (p.His194Arg), c.739C $>\mathrm{A} \quad$ (p.Arg247Ser), c.1121T $>\mathrm{A} \quad$ (p.Phe374Tyr), c.2296A $>$ C (p.Thr766Pro), c.2353C >A (p.Pro785Thr) and c.2365A >G (p.Ile789Val). Additionally, EPAS1 c.1591C>A (p.Pro531Thr) known to affect a critical hydroxylation site of HIF-2 $\alpha$ and previously associated with PGL (Toledo et al. 2013) was generated as a positive control. Plasmids were sequenced to confirm the presence of WT or variant sequences and confirm an in-frame GFP tag. Commercially available renilla luciferase reporter for vascular endothelial growth factor A (VEGFA) promoter - associated with hypoxia signaling - was obtained (\#S722028, SwitchGearGenomics, CA, USA).

\section{Cell culture and transfection}

HEK293 and HeLa cells were both cultured in DMEM (Life Technologies) with 10\% fetal bovine serum (FBS). PC12 cells required RPMI (Life Technologies) supplemented with 5\% FBS and 10\% heat-inactivated horse serum (Life Technologies). Experiments involving plasmid transfection began with seeding of $1 \times 10^{5}$ cells/well for HEK293 and HeLa cells, whereas PC12 cells were plated at $3 \times 10^{5}$ cells/ well in six-well plate $24 \mathrm{~h}$ prior to $2 \mu \mathrm{g} /$ well of plasmid DNA transfection experiments using OptiMEM (Life Technologies) and Lipofectamine 2000 (Life Technologies). Immediately upon transfection of plasmid DNA, designated 6-well plates were exposed to low-oxygen environment using hypoxia chamber XVIVO system (BioSpherix, NY, USA) which was used to incubate cells in $1 \% \mathrm{O}_{2}$ at $37^{\circ} \mathrm{C}$ for $48 \mathrm{~h}$. The level of $\mathrm{O}_{2}, \mathrm{~N}_{2}, \mathrm{CO}_{2}$ were logged in real-time using Oxycycler Watview software (BioSpherix) to ensure appropriate conditions were maintained.

\section{Stability of HIF-2 $\alpha$ variants}

Whole cell lysates were prepared using RIPA buffer and quantified to assess stability of transfected GFP-tagged WT
HIF-2 $\alpha$ under normoxic conditions $\left(21 \% \mathrm{O}_{2}\right)$, compared with hypoxic conditions $\left(1 \% \mathrm{O}_{2}\right)$ as a positive control. Stability of GFP-tagged HIF- $2 \alpha$ variants was assessed using cells conditioned under normoxic conditions. Extracts were mixed with NuPAGE® LDS sample buffer (Invitrogen) and dithiothreitol and incubated at $95^{\circ} \mathrm{C}$ for $5 \mathrm{~min}$ and separated by SDS-PAGE (4-12\% NuPAGE Bis-Tris gels, Invitrogen) under reducing conditions. Proteins were transferred (nitrocellulose membrane) and the membrane blocked with 5\% skim milk (in TBST) for $1 \mathrm{~h}$ at room temperature. The membranes were probed with the following antibodies: GFP (dilution 1:2000, Roche (11814460001)), and GAPDH (dilution 1:5000, Cell Signaling (D16H11)) and incubated overnight at $4^{\circ} \mathrm{C}$. Immunoblots were washed three times with TBST for 5-10 min and incubated with the relevant secondary antibody conjugated to horseradish peroxidase (HRP). Blots were then washed (three times in TBST for $5 \mathrm{~min}$ ) and protein detected (ECL Plus Western Blotting Detection Reagent (GE Healthcare)) on a LAS-3000 (Fujifilm, Brookvale, Australia).

\section{Co-immunoprecipitation}

To determine whether mutant HIF- $2 \alpha$ disrupts the normal interaction of HIF- $2 \alpha$ with pVHL or HIF-1 $\beta$, GFP-tagged WT or mutant HIF- $2 \alpha$ were blotted after endogenous pVHL or HIF-1 $\beta$ mediated pulldown. Briefly, $48 \mathrm{~h}$ posttransfection, cells were washed (PBS), pelleted and lysed using co-immunoprecipitation (Co-IP) buffer (20 mM Tris pH 7.5, $150 \mathrm{mM} \mathrm{NaCl}, 1 \mathrm{mM}$ EGTA, 1 mM EDTA, $0.1 \%$ Triton X100). Dynabeads ${ }^{\circledR} \mathrm{M}-280$ sheep anti-rabbit IgG (\#026102, Life Technologies) were incubated with either rabbit IgG antibody (dilution 1:2000, \#31460, Thermo-Fisher) for negative control, pVHL polyclonal rabbit antibody (dilution 1:2000, \#2738, Cell Signaling Technology) or HIF-1 $\beta$ polyclonal rabbit antibody (dilution 1:2000, \#5537, Cell Signaling Technology) for $2 \mathrm{~h}$ prior to washing; then incubated overnight with cell extracts at $4^{\circ} \mathrm{C}$ under gentle rotation. Proteins not associated with pVHL or HIF- $1 \beta$ were removed $(3 \times 10$ min gentle agitation washes) using Co-IP lysis buffer with a higher salt concentration $(500 \mathrm{mM} \mathrm{NaCl})$. To remove immunoprecipitated material from beads, cell lysates were mixed with NuPAGE® LDS sample buffer (Invitrogen) and dithiothreitol and incubated at $95^{\circ} \mathrm{C}$ for $5 \mathrm{~min}$. Extracts were removed from beads and separated by SDS-PAGE (4-12\% NuPAGE Bis-Tris gels, Invitrogen) under reducing conditions. Proteins were transferred, blocked, probed and protein detected as outlined previously.

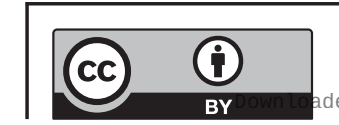

This work is licensed under a Creative Commons Attribution 4.0 International License. 


\section{Cyclohexamide treatment}

To assess the half-life of GFP-tagged WT or mutant HIF- $2 \alpha$ proteins in plasmid transfected HEK293 cells, $100 \mu \mathrm{g} / \mathrm{mL}$ of cycloheximide (CHX; \#C0934, Sigma) was added to inhibit protein synthesis at 60,30 and $10 \mathrm{~min}$ prior to protein extraction.

\section{Structural modeling}

To assess the interaction between pVHL and EPAS1 residue p.Arg247, the structure of human HIF-2 $\alpha$ was extracted from the crystal structure of HIF- $2 \alpha$ heterodimerized with ARNT-C-terminal PAS domain (PDB code: 3F1P, chain A) (Scheuermann et al. 2009). The engineered Glu247 found in HIF-2 $\alpha$ crystal structure was changed back to Arg247. The structure covers the PAS-B domain (residues 236 from 349 ). Thus, a homology model for the bHLH and PAS-A domains of HIF- $2 \alpha$ (residues 27-235) was built using the crystal structure of mouse Hif- $2 \alpha$, extracted from the heterodimeric complex HIF-2 $\alpha$-ARNT crystal structure (PDB code: 4ZP4, chain B) (Wu et al. 2015). The sequence identity between mouse Hif- $2 \alpha$ and human HIF- $2 \alpha$ is $98 \%$ over the bHLH-PAS domains. The structure of pVHL was extracted from the crystal structure of hydroxylated HIF- $2 \alpha$ peptide (residues 523 to 541) bound to the pVHL/ elongin-C/elongin-B complex (PDB code 6BVB; chain V) (Tarade et al. 2018). The docking server ClusPro was used to dock pVHL (defined as the ligand) on HIF-2 $\alpha$ (defined as a receptor). 101 models were generated. Models for which an interface was predicted between pVHL and HIF- $2 \alpha$ that include residues on pVHL known to be in interaction with elongin- $\mathrm{C}$ in $\mathrm{pVHL} /$ elongin-C/elongin-B complex were excluded. These residues are 79-81, 132, 152-166, 169, 178-184, and 188 on pVHL. Models for which an interface was predicted between pVHL and HIF- $2 \alpha$ that include residues on HIF- $2 \alpha$ known to be in interaction with DNA or ARNT in the crystal structure of DNA-bound HIF- $2 \alpha$-ARNT structures were excluded from the set of models. These residues are 73, 76, 79, 80-97, 100-108 and 112 on HIF-2 $\alpha$. Finally, three models were remaining. The structures and interaction of three models have been optimized using energy minimization with Maestro software (Schrödinger, D.E. Shaw Research, NY). The lowest energy model has been used for our structural analysis. The dimer elongin $\mathrm{C}$-elongin $\mathrm{B}$ was positioned on pVHL according to the crystal structure pVHL/elongin-C/ elongin-B (PDB code 6BVB; chain V) (Tarade et al. 2018). Images were created with Pymol.

\section{Luciferase assay}

Impact of germline EPAS1 variants on transcriptional activity of mutant HIF- $2 \alpha$ relative to WT was assessed. Promoter activity of VEGFA was selected as a downstream transcription target of HIF-2 $\alpha$ (Maxwell et al. 1999, Meneses $\&$ Wielockx 2016). Along with the WT or variant GFPtagged EPAS1 plasmids, 10 ng of pLightSwitch_VEGFA and $400 \mathrm{ng}$ of pGL3-Basic were also added into the transfection mixture. After $48 \mathrm{~h}$ of incubation, passive lysis buffer was used to harvest cells for luciferase assay.

\section{RNA extraction and qRT PCR}

Gene expression analyses were performed to examine whether stabilization of HIF- $2 \alpha$ induced hypoxiaresponsive genes including cyclin D1 coding CCND1 (encoding cyclin D1) and SLC2A1 (encoding glucose transporter 1). Taqman gene expression assays (ThermoFisher) were used perform qRT-PCR using probes specific to CCND1 (\#Hs00765553_m1), SLC2A1 (Hs00892681_m1) and ACTB (\#Hs99999903_m1, beta actin, endogenous control).

\section{Statistical analyses}

Minor allele frequencies of EPAS1 variants in our cases and gnomAD (non-cancer) European non-Finnish controls were compared using the Fisher exact test. HIF-2 $\alpha$ variant stability in normoxia was measured by densitometry of Western blots, corrected for GAPDH in each case and expressed relative to the value of WT HIF- $2 \alpha$ under hypoxia as mean \pm s.D. of $n=3$ experiments. HIF- $2 \alpha$ variant interaction with pVHL by co-immunoprecipitation was also measured by densitometry of Western blots, corrected for $\mathrm{pVHL}$ and expressed relative to the value of WT HIF- $2 \alpha$ under normoxia as mean \pm S.D. of $n=3$ experiments. Differences in protein measurements were analyzed by Student's t-test using GraphPad Prism version 7.02.

\section{Results}

\section{Incidental identification of germline EPAS1 variants}

During the validation of a multigene panel for next generation sequencing (NGS), we found six Australian PPGL patients who had EPAS1 germline variants (c.581A $>\mathrm{G}$ (p.His194Arg), c.739C $>$ A (p.Arg247Ser), c.1121T $>A$

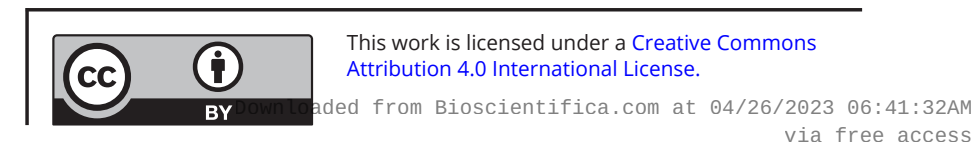


Table 1 Germline EPAS1 variants in individuals with previously identified PPGL-associated germline drivers.

\begin{tabular}{|c|c|c|c|c|}
\hline \multirow[b]{2}{*}{ Patient \# } & \multirow[b]{2}{*}{ Features } & \multirow[b]{2}{*}{ Germline driver gene variant } & \multicolumn{2}{|c|}{ Germline EPAS1 variant } \\
\hline & & & Nucleotide ${ }^{a}$ change & Amino acidb change \\
\hline 1 & $P C$ & VHL p.Trp117Ser & c. $581 \mathrm{~A}>\mathrm{G}$ & p.His194Arg \\
\hline \multirow[t]{2}{*}{2} & PGL & $S D H B$ C. $72+1 G>T$ & c. $739 C>A$ & p.Arg247Ser \\
\hline & & & C. $1121 \mathrm{~T}>\mathrm{A}$ & p.Phe374Tyr \\
\hline 3 & $P C$ & SDHB p.Gly96Ser & C. $1121 \mathrm{~T}>\mathrm{A}$ & p.Phe374Tyr \\
\hline 4 & PGL & SDHB p.Ile127Ser & c. $1121 \mathrm{~T}>\mathrm{A}$ & p.Phe374Tyr \\
\hline 5 & PCmet & SDHB p.Gln24* & c. $2296 \mathrm{~A}>\mathrm{C}$ & p.Thr766Pro \\
\hline 6 & PGL & SDHB p.Pro197Arg & C. $2296 A>C$ & p.Thr766Pro \\
\hline
\end{tabular}

aNCBI Reference Sequence: NM_001430.5; bNCBI Reference Sequence: NP_001421.2.

met, known to have metastatic disease; PC, pheochromocytoma; PGL, paraganglioma.

(p.Ph374Tyr), or c.2296A>C (p.Thr766Pro)) occurring together with previously identified PPGL-associated germline mutations in other driver genes (Table 1). Notably, five of six of these patients had germline $S D H B$ mutations. For two cases annotated clinical data were available. Case \#1 (EPAS1 variant c.581A>G, p.His194Arg) together with $V H L$ mutation c.350G $>$ C, p.Trp117Ser) was a man who had resection of a right phaeochromocytoma aged 30 years, and who also had bilateral renal masses, a pancreatic neuroendocrine tumor and recurrent hemangioblastomas consistent with diagnosis of VHL syndrome; his most recent hematocrit values have ranged between 0.45 and 0.52 (normal range 0.39-0.54). Case \#3 (EPAS1 variant c.1121T>A, p.Phe374Tyr together with SDHB mutation c.286G $>$ A, p.Gly96Ser) was a woman who had resection of a carotid body paraganglioma at age 52 years, without recurrence 15 years later; her most recent hematocrit values have ranged between 0.47 and 0.49 (normal range 0.35-0.47). It was not possible to verify familial transmission of the EPAS1 variant in either case.

On the basis of our preliminary findings that germline EPAS1 variants may occur together with other germline PPGL predisposition alleles, we extended our EPAS1 sequence analysis to a larger cohort of 300 individuals with PPGL (Australian $(n=133$, includes Table 1 subjects), German $(n=45)$, Italian $(n=52)$ and Polish $(n=70)$ subsets; Table 2 and Supplementary Tables 1,2 , see section on supplementary materials given at the end of this article). As shown in Table 2, an additional 15 subjects (of whom five also had germline $S D H x$ mutations) were found with germline EPAS1 alleles: one with EPAS1 c.830C $>$ T (p.Ala277Val), two with c.1121T>A (p.Ph374Tyr), one with c.1963G>A (p.Gly655Arg), ten with c.2296A>C (p.Thr766Pro) two of whom $(\# 19,20)$ also carried c.2353C $>\mathrm{A}$ (p.Pro785Thr), and one with c.2365A $>\mathrm{G}$ (p.Ile789Val). Combining both cohorts, germline EPAS1 variants were found no more often in subjects with an $S D H B$ mutation (six of 75 subjects), compared with subjects without an $S D H B$ mutation (15 of 225, $P=0.7$ ); nor was prevalence of germline EPAS1 variants different in those with germline mutations in $V H L / S D H x$ genes (11 of 176 subjects) compared with others (10 of 124 subjects).

Using in silico tools (Table 3), EPAS1 variant c.739C $>$ A (p.Arg247Ser) was consistently predicted to be pathogenic, whereas c.581A>G (p.His194Arg), c.830C $>T$ (p.Ala277Val) and c.1121T $>$ A (p.Phe374Tyr) substitutions were predicted to be pathogenic by some but not all tools. EPAS1 variants c.1963G>A (p.Gly655Arg), c.2296A $>$ C (p.Thr766Pro), c.2353C >A (p.Pro785Thr) and c.2365A $>\mathrm{G}$ (p.Ile789Val) were predicted to be benign by all prediction tools.

We then compared allelic frequencies of these variants in PPGL patients with those from the genome aggregation database samples from individuals who were not ascertained for having cancer in a cancer study (gnomAD v2.1.1 non-cancer; Table 3) (Karczewski et al. 2020). We note EPAS1 variants c. $2296 \mathrm{~A}>\mathrm{C}$ and c. $2353 \mathrm{C}>\mathrm{A}$ had allelic frequencies in gnomAD of $>1 \%$, consistent with being common polymorphisms. Moreover, since there is significant ethnic variation of many of these EPAS1 variants in non-cancer gnomAD (Supplementary Table 3), we confined statistical comparison to our PPGL cases against European non-Finnish controls (i.e. the relevant ethnic background for our cases). As shown in Table 3, c.581A $>$ G (p.His194Arg), c.830C $>$ T (p.Ala277Val), c.2353C $>$ A (p.Pro785Thr) and c.2365A $>\mathrm{G}$ (p.Ile789Val) were more common in PPGL cases than controls. EPAS1 c.739C $>$ A (p.Arg247Ser) was not seen in gnomAD, although two other rare variants are noted at this codon (c.739C >T (p.Arg247Cys) MAF $8 \times 10^{-6}$; and c.740G $>$ A (p.Arg247His) MAF $8.7 \times 10^{-5}$ ). Although EPAS1 variant c.2296A>C (p.Thr766Pro) has uncertain annotation in gnomAD (i.e. it is deemed to be a multi-nucleotide variant), we confirmed this variant by Sanger sequencing in each PPGL case.

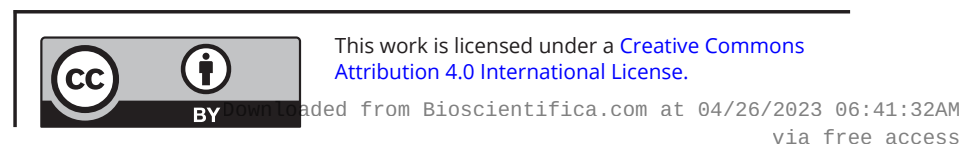


Table 2 Germline EPAS1 variants in validation cohort.

\begin{tabular}{|c|c|c|c|}
\hline \multirow[b]{2}{*}{ Patient \# } & \multirow{2}{*}{$\begin{array}{l}\text { Germline } \\
\text { driver gene } \\
\text { variant }\end{array}$} & \multicolumn{2}{|c|}{ Germline EPAS1 variant } \\
\hline & & Nucleotidea change & Amino acid ${ }^{b}$ change \\
\hline 7 & SDHB & c. $830 \mathrm{C}>\mathrm{T}$ & p.Ala277Val \\
\hline 8 & SDHC & c. $1121 \mathrm{~T}>\mathrm{A}$ & p.Phe374Tyr \\
\hline 9 & SDHD & C. $2296 \mathrm{~A}>\mathrm{C}$ & p.Thr766Pro \\
\hline 10 & SDHD & C. $2296 \mathrm{~A}>\mathrm{C}$ & p.Thr766Pro \\
\hline 11 & SDHD & C. $2296 \mathrm{~A}>\mathrm{C}$ & p.Thr766Pro \\
\hline 12 & None known & C. $1121 \mathrm{~T}>\mathrm{A}$ & p.Phe374Tyr \\
\hline 13 & None known & c.1963G >A & p.Gly655Arg \\
\hline 14 & None known & C. $2296 A>C$ & p.Thr766Pro \\
\hline 15 & None known & C. $2296 \mathrm{~A}>\mathrm{C}$ & p.Thr766Pro \\
\hline 16 & None known & C. $2296 \mathrm{~A}>\mathrm{C}$ & p.Thr766Pro \\
\hline 17 & None known & C. $2296 \mathrm{~A}>\mathrm{C}$ & p.Thr766Pro \\
\hline 18 & None known & C. $2296 \mathrm{~A}>\mathrm{C}$ & p.Thr766Pro \\
\hline \multirow[t]{2}{*}{19} & None known & C. $2296 \mathrm{~A}>\mathrm{C}$ & p.Thr766Pro \\
\hline & & c. $2353 C>A$ & p.Pro785Thr \\
\hline \multirow[t]{2}{*}{20} & None known & C. $2296 A>C$ & p.Thr766Pro \\
\hline & & c. $2353 C>A$ & p.Pro785Thr \\
\hline 21 & None known & c. $2365 A>G$ & p.lle789Val \\
\hline
\end{tabular}

aNCBI Reference Sequence: NM_001430.5; bNCBI Reference Sequence: NP_001421.2.

\section{Estimated penetrance of EPAS1 variants}

We next applied Bayesian principles (Minikel et al. 2016) that we previously used for SDHx variants (Benn et al. 2018), to estimate the lifetime penetrance of PPGL for EPAS1 variants c.1121T>A (p.Phe374Tyr) and c.2353C>A (p.Pro785Thr), taking into account allelic frequencies in our cases vs European non-Finnish gnomAD controls, and assuming estimated population PPGL prevalence of 1/3000 (Benn et al. 2018). Using these calculations, c.2353C>A (p.Pro785Thr) has a modest estimated lifetime penetrance for PPGL of $0.22 \%$ (CI $0.03-1.13 \%$ ) whereas c.1121T>A (p.Phe374Tyr) has an estimated lifetime penetrance of only $0.05 \%$ (CI $0.02-0.13 \%$, i.e. not significantly different from population prevalence).

\section{Hypoxia stabilizes WT HIF-2 $\alpha$ protein compared to normoxia}

To examine the stability of the identified EPAS1 variants in normoxia, we generated GFP-tagged expression plasmids for each variant (excepting the predicted benign variants p.Ala277Val and p.Gly655Arg) and transfected them into HEK293, PC12 and HeLa cells. We included two positive controls in each experiment: (i) the somatic gain-of-function EPAS1 mutant p.Pro531Thr in normoxia and (ii) WT HIF-2 $\alpha$-GFP transfected in cells cultured under hypoxic (1\%) conditions. We validated that WT-HIF- $2 \alpha$ was sensitive to oxygen concentrations, since it was undetectable in transfected cells maintained in normoxia and progressively increased in cells maintained at 5 or $1 \%$ oxygen, respectively, (Supplementary Fig. 1). As shown by representative Western blots in Fig. 1, HIF-2 $\alpha$ mutants p.Arg247Ser, p.Phe374Tyr and p.Pro785Thr were stable in normoxia in all cellular backgrounds, HEK293 (A), PC12 (B) and HeLa cells (C). When measured by densitometry, levels of these three mutant proteins were not significantly different from p.Pro531Thr or hypoxic WT HIF- $2 \alpha$ in HEK293 and HeLa cells, whereas p.Arg247Ser and p.Pro785Thr were mildly lower than controls in PC12 cells (Supplementary Fig. 2). In contrast, HIF-2 $\alpha$ mutants p.His194Arg, p.Thr766Pro and p.Ile789Val were not stable in normoxia in any cellular background (Fig. 1 and Supplementary Fig. 2).

Transfected HEK293 cells were treated with cyclohexamide to confirm that these HIF-2 $\alpha$ levels are not explained by de novo protein synthesis. As shown

Table 3 EPAS1 variant characteristics.

\begin{tabular}{|c|c|}
\hline EPAS1/HIF- $2 \alpha$ variant & $\begin{array}{c}\text { MAFa in combined } \\
\text { cohortb }^{b}\end{array}$ \\
\hline p.His194Arg & $0.0018 * *$ \\
\hline p.Arg247Ser & 0.0017 \\
\hline p.Ala277Val & $0.0017 *$ \\
\hline p.Phe374Tyr & 0.0087 \\
\hline p.Gly655Arg & 0.0017 \\
\hline p.Thr766Pro & 0.0206 \\
\hline p.Pro785Thr & $0.0034 *$ \\
\hline p.lle789Val & $0.0017 * *$ \\
\hline
\end{tabular}

\begin{tabular}{lc}
\hline \multicolumn{2}{c}{ MAF in gnomADc } \\
\cline { 1 - 1 } \multicolumn{1}{c}{ All } & European non-Finnish \\
\cline { 1 - 1 } 0.00007 & 0 \\
$\mathrm{np}$ & $\mathrm{np}$ \\
0.00002 & 0.00003 \\
0.0039 & 0.0059 \\
0.0002 & 0.0004 \\
0.06 & 0.0166 \\
0.014 & 0.0005 \\
0.00002 & 0.00003 \\
\hline
\end{tabular}

\begin{tabular}{|c|c|c|}
\hline \multicolumn{3}{|c|}{ In silico tools } \\
\hline SIFTd & PolyPhen-2e & Mutation Tasterf \\
\hline D & PD & DC \\
\hline D & PD & DC \\
\hline $\mathrm{T}$ & B & DC \\
\hline $\mathrm{T}$ & B & DC \\
\hline $\mathrm{T}$ & B & $P$ \\
\hline $\mathrm{T}$ & B & $P$ \\
\hline $\mathrm{T}$ & B & $P$ \\
\hline $\mathrm{T}$ & B & $P$ \\
\hline
\end{tabular}

Statistical comparison between EPAS1 variant MAF in PPGL cases and gnomAD European-non-Finnish controls * $P<0.05 ; * \star P<0.001$ aMAF, minor allele frequency (number of cases with allelic variant/total number of alleles); ${ }^{b}$ combined cohort of PPGL cases from Australia, Germany, Italy, and Poland; cgnomAD v.2.1 (non-cancer); dVaser et al. (2016) SIFT missense predictions for genomes; eAdzhubei et al. (2010) A method and server for predicting damaging missense mutations; fSchwarz et al. (2014) Mutation Taster2: mutation prediction for the deep-sequencing age. $\mathrm{B}$, benign; D, deleterious; DC, disease causing; Np, not present; $\mathrm{P}$, polymorphism; PD, possibly deleterious; $T$, tolerate.

https://erc.bioscientifica.com https://doi.org/10.1530/ERC-20-0280 (c) 2021 The authors Published by Bioscientifica Ltd. Printed in Great Britain
This work is licensed under a Creative Commons Attribution 4.0 International License. 
A
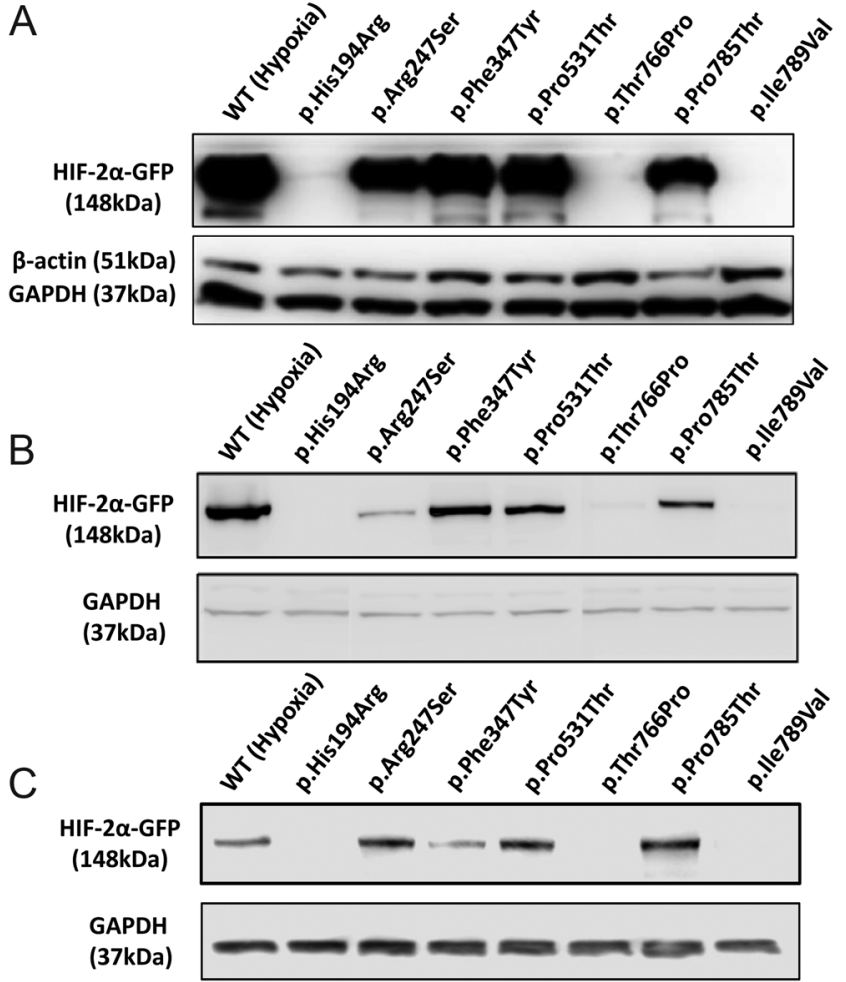

Figure 1

Stability of HIF-2 $\alpha$ variants in normoxia. (A) Representative Western blots of lysates from HEK293 cells, transfected with EPAS1 variants and cultured in normoxia, indicated robust expression of GFP-tagged HIF- $2 \alpha$ mutants c.739C >A (p.Arg247Ser), c.1121T>A (p.Phe374Tyr) and c.2353C >A (p.Pro785Thr) relative to pathogenic control p.Pro531Thr, as well as WT HIF-2 $\alpha$ in lysates from cells cultured in hypoxia. Endogenous housekeeper proteins B-actin and GAPDH are shown subsequently. Similar stability of HIF-2 $\alpha$ mutants were observed in PC12 (B) and HeLa (C) cells, albeit expression level of c.1121T>A (p.Phe374Tyr) was lower for the latter.

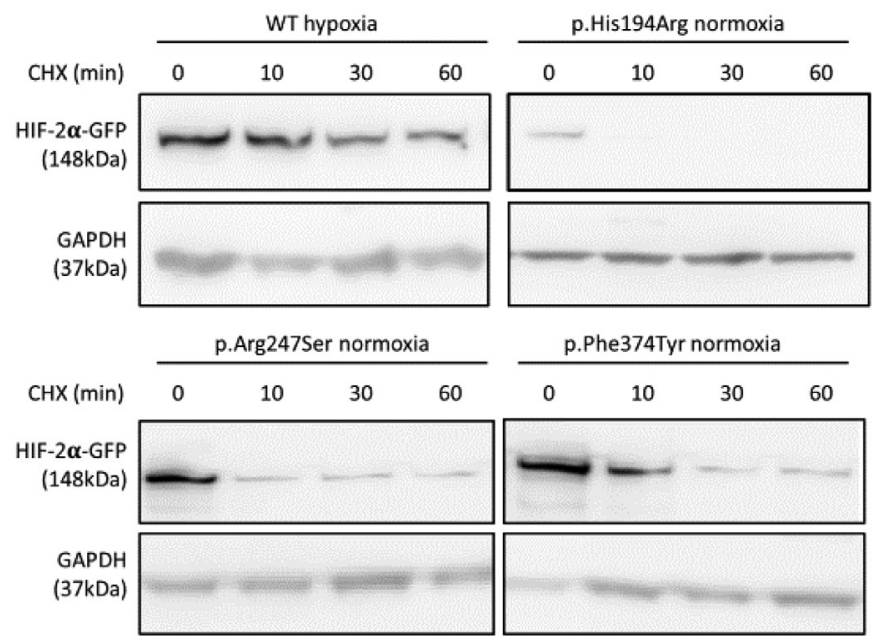

in Fig. 2, HIF-2 $\alpha$ variants p.His194Arg, p.Thr766Pro and p.Ile789Val were all rapidly degraded in normoxia 60 min after cycloheximide treatment. In contrast, HIF- $2 \alpha$ variants p.Arg247Ser, p.Phe374Tyr and p.Pro785Thr were stable over the course of cycloheximide treatment, similar to the positive control p.Pro531Thr; the stability of WT HIF-2 $\alpha$ under hypoxia is shown for reference.

\section{Interaction between HIF-2 $\alpha$ mutants and $\mathrm{pVHL}$ is retained except for variant p.Arg247Ser}

Under normoxic condition, HIF- $2 \alpha$ is regulated through pVHL mediated degradation. We hypothesized that stability of p.Arg247Ser, p.Phe374Tyr and p.Pro785Thr HIF- $2 \alpha$ mutants in normoxia may be due to disrupted interaction between pVHL and HIF- $2 \alpha$. This was assessed by co-immunoprecipitation of HIF- $2 \alpha$ mutants from HEK293 cells using magnetic beads coupled to anti-pVHL antibodies. WT HIF- $2 \alpha$ extracted from normoxic cells was used as a positive control (Fig. 3 and Supplementary Fig. 3). As expected, gain-of-function positive control p.Pro531Thr HIF-2 $\alpha$ mutant did not associate with pVHL in normoxia, due to absence of the prolyl hydroxylation site at residue 531 of HIF-2 $\alpha$ (Fig. 3). The novel variant p.Arg247Ser also showed diminished interaction with pVHL. Interestingly, p.Phe374Tyr and p.Pro785Thr HIF-2 $\alpha$ mutants that were stable in normoxia retained their interaction with pVHL (Fig. 3). The other HIF-2 $\alpha$ mutants p.His194Arg, p.Thr766Pro and p.Ile789Val also retained interaction with pVHL.

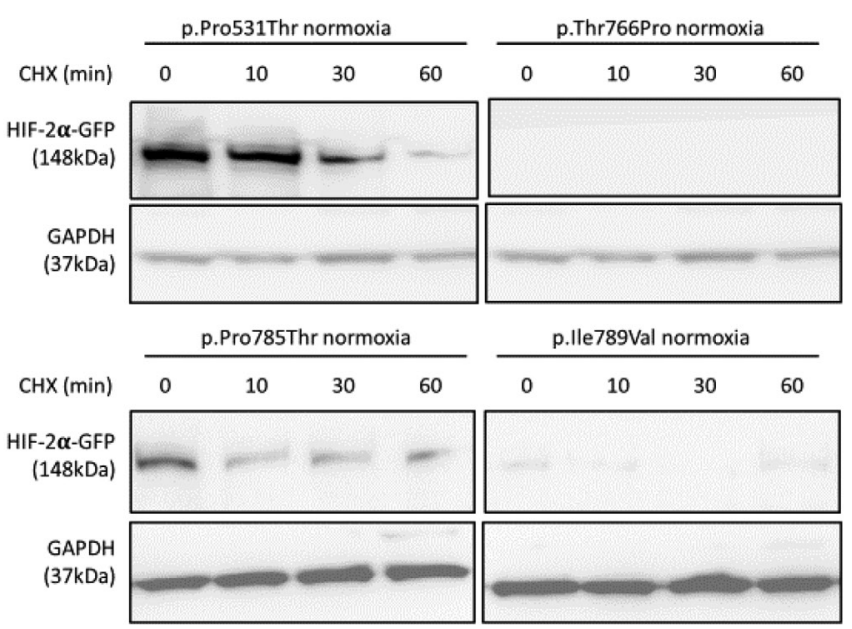

Figure 2

Stability of HIF- $2 \alpha$ variants following cycloheximide. Cells exposed to cycloheximide (CHX) over periods of time indicated prolonged stability of WT HIF-2 $\alpha$ in hypoxia, and HIF-2 $\alpha$ variants c.739C>A (p.Arg247Ser), c.1121T>A (p.Phe374Tyr), p.Pro531Thr, c.2353C>A (p.Pro785Thr) in normoxia.

https://erc.bioscientifica.com
https://doi.org/10.1530/ERC-20-0280 2021 The authors

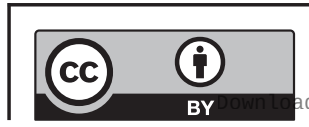

This work is licensed under a Creative Commons Attribution 4.0 International License. 


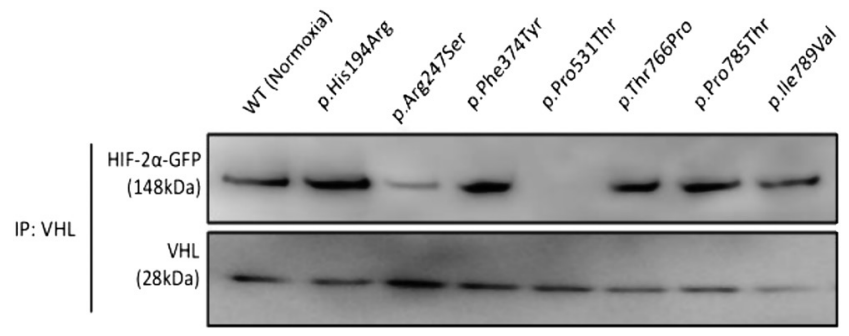

Figure 3

Interaction of HIF-2 $\alpha$ variants with pVHL. Representative Western blot following co-immunoprecipitation of GFP-tagged HIF-2 $\alpha$ by anti-pVHL antibody. HEK293 cells transfected with WT HIF- $2 \alpha$ and cultured in normoxia ( $48 \mathrm{~h}$ ) were used as a positive control. The negative control was HIF-2 $\alpha$ variant p.Pro531Thr. Reduced HIF-2 $\alpha-$ pVHL interaction was only observed for HIF-2 $\alpha$ variant c.739C>A (p.Arg247Ser).

\section{Structural modeling identifies a potential interface between EPAS1 p.Arg247 and pVHL}

We investigated the possible disrupted interaction between pVHL and HIF- $2 \alpha$ for mutant p.Arg247Ser. A crystal structure is available for the heteromultimeric complex pVHL/elongin-C/elongin-B in interaction with the 523-540 fragment of HIF-2 $\alpha$ (Tarade et al. 2018). We also examined other possible binding modes between pVHL and HIF- $2 \alpha$ by in silico building the complex formed by these two proteins. The best model includes an interface between the L7 loop of the pVHL $\beta$-domain and the PAS-B domain of HIF-2 $\alpha$ (Fig. 4A). This predicted binding site for HIF- $2 \alpha$ on pVHL is about $15 \AA$ away from the HIF- $2 \alpha$ binding site described in the crystal structure pVHL/elongin-C/elongin-B/HIF-2 $\alpha$ (Tarade et al. 2018). We found that Arg247 mediates two critical interactions between HIF- $2 \alpha$ and pVHL: a salt bridge with Asp143 and a hydrogen bond with Gln145 on pVHL (Fig. 4B).

\section{Interaction between HIF-2 $\alpha$ mutants and ARNT is unaltered}

Cellular hypoxic response requires heterodimerization of HIF- $\alpha$ with ARNT (HIF- $\beta$ ) to act as a transcription factor for activation of various genes. Due to the lack of functional studies of HIF- $2 \alpha$ and ARNT pairing in context of PPGL, it was unclear whether our EPAS1 variants affected this interaction. To investigate this in normoxia, GFP-tagged WT or mutant HIF- $2 \alpha$ proteins were overexpressed by tripling transfection input to $6 \mu \mathrm{g} / 1 \times 10^{5}$ HEK293 cells to ensure adequate amounts of proteins. Then, co-immunoprecipitation was performed using anti-ARNT on magnetic beads. Subsequent Western blotting analyses showed no obvious difference between various HIF- $2 \alpha$ mutants (Supplementary Fig. 4). This indicated that
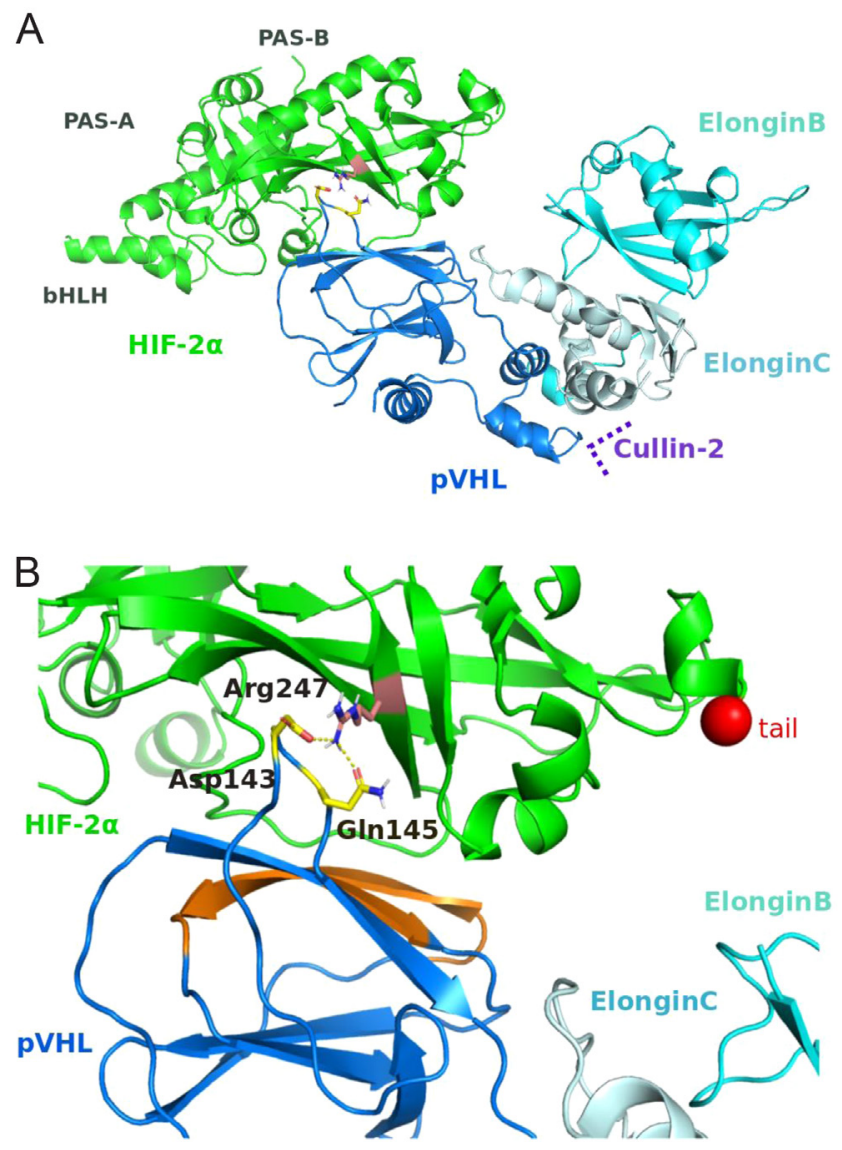

Figure 4

Model of association between HIF-2 $\alpha$ and pVHL. (A) Global view of the modeled heteromeric complex HIF-2-pVHL-ElonginC-ElonginB in cartoon representation. For information, the position of the Cullin-2 is indicated according to the crystal structure of Cul2-Rbx1-EloBC-VHL ubiquitin ligase complex (PDB code: 5N4W). Arg247 of HIF-2 $\alpha$, Gln145 and Asp143 of pVHL are represented in stick. (B) Detailed view of the specific interactions between HIF-2 $\alpha$ and pVHL. The yellow dash lines represent the electrostatic interactions. The orange on $\mathrm{PVHL}$ shows the interfacial residues that interact with HIF-2 $\alpha$ peptide (523-541) in the crystal structure of the heteromeric HIF-2 $\alpha / p V H L /$ elongin-C/elongin-B complex (PDB code: 6BVB) (Tarade et al. 2018). The red sphere indicates the last element of the structure of HIF-2 $\alpha$ (residue 360 ) that has been experimentally determined and modeled in our study (there are no structural data available for the segment 361-522).

HIF- $2 \alpha$-ARNT interaction was not altered by these EPAS1 variants.

\section{HIF-2 $\alpha$ induced transcription}

Transactivation by HIF- $2 \alpha$ mutants was firstly assessed by means of a HRE-containing reporter gene. HEK293 cells were transfected with WT or mutant EPAS1 vectors together with pLightSwitch VEGFA, containing the VEGFA promoter upstream of the renilla reporter. Significantly higher reporter activity was observed in lysates from 
A

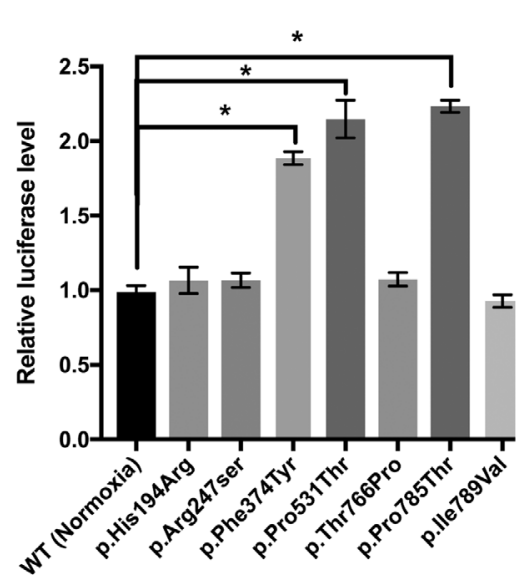

B CCND1

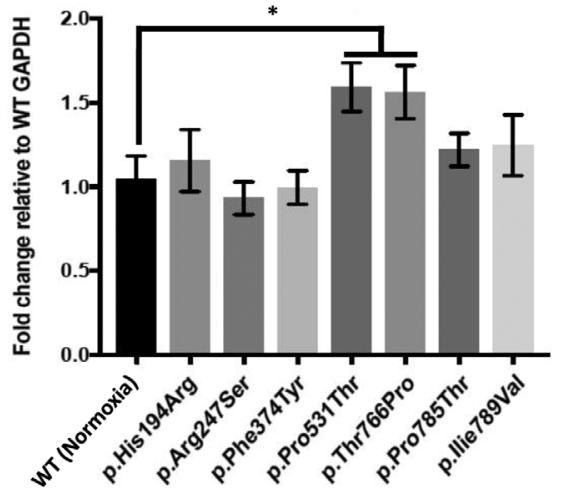

C

SLC2A1

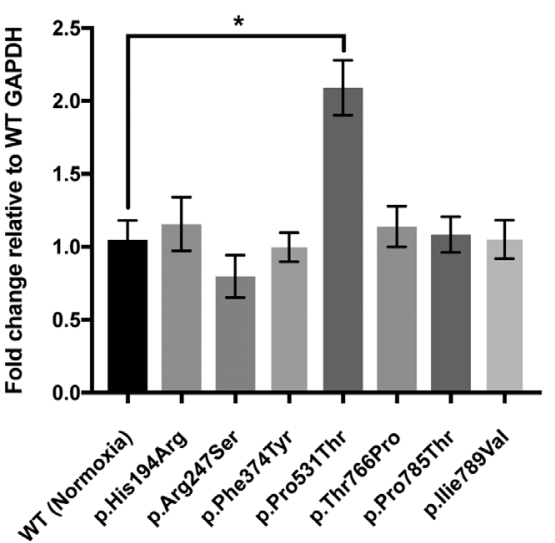

Figure 5

Transcriptional regulation by HIF-2 $\alpha$ variants. (A) VEGFA-LUC was transfected in HEK293 cells together with WT or HIF-2 $\alpha$ variants as shown, and luciferase was measured in cell lysates after $48 \mathrm{~h}$. Compared to WT HIF- $2 \alpha$, significant transduction of VEGFA-LUC was observed in samples with p. HIF-2 $\alpha$ variants Phe374Tyr and c.2353C>A (p.Pro785Thr) alongside p.Pro531Thr that served as positive control ( $n=3$, * $P<0.05$ ). (B) Gene expression assay performed on samples from HEK293 cells that were induced to express WT or mutant HIF-2 $\alpha$ in normoxia over 48 h. (A) Compared to WT HIF-2 $\alpha$ CCND1 expression was significantly induced after transfection of somatic gain-of-function p.Pro531Thr HIF-2 $\alpha$ mutant (positive control) or our novel c.2296A>C (p.Thr766Pro) variant $(n=3, * P<0.05)$. (B) Significant induction of SLC2A1 mRNA was also observed in p.Pro531Thr HIF-2 $\alpha$ expressing cells ( $n=3, * P<0.05)$, although no significant changes were observed in our selected EPAS1 variants ( $n=3, P>0.05)$.

cells transfected with EPAS1/HIF-2 $\alpha$ p.Phe374Tyr, p.Pro785Thr and positive control p.Pro531Thr mutant (Fig. 5A). These results somewhat reflected the effect of HIF- $2 \alpha$ mutants on protein stability in normoxia, with the exception of p.Arg247Ser which was not associated with increased reporter transactivation despite apparent protein stability.

To further assess the consequences of stable HIF- $2 \alpha$ in normoxia, changes in expression of the genes associated with pseudohypoxia were quantified. This involved extracting total RNA from HEK293 cells transiently transfected with GFP-tagged WT or mutant HIF-2 $\alpha$ over $48 \mathrm{~h}$ and performing RT for cDNA conversion, followed by quantitative real-time PCR. Two selected genes were; cyclin D1 (CCND1) and solute carrier family 2 member 1 (SLC2A1) encoding for the glucose transporter protein type 1 (GLUT1), both previously used by Toledo et al. (2013) as indicator of cellular response to hypoxia. From our selection of germline EPAS1/HIF-2 $\alpha$ variants, only p.Thr766Pro alongside p.Pro531Thr positive control HIF- $2 \alpha$ mutant was able to induce significant CCND1 expression relative to WT $(n=3, P<0.05)$ (Fig. 5B). Significant induction of SLC2A1 was observed only in our somatic gain-of-function mutation p.Pro531Thr relative to cells transfected with WT EPAS1 in normoxia $(n=3$, $P<0.05$ ) (Fig. 5C).

\section{Discussion}

The role of EPAS1/HIF-2 $\alpha$ in PPGL is still emerging, and the pathogenic potential of germline EPAS1 variants is not well understood. In this study we have systematically assessed the functional effect of germline EPAS1 variants c.581A $>$ G (p.His194Arg), c.739C $>$ A (p.Arg247Ser), c.1121T $>$ A (p.Phe374Tyr), c.2296A $>C$ (p.Thr766Pro), c.2353C $>A$ (p.Pro785Thr) and c.2365A $>$ G (p.Ile789Val) identified in patients with PPGL. Collectively, our data show that p.Arg247Ser, p.Phe374Tyr and p.Pro785Thr each share some features in common with the known oncogenic EPAS1 mutation p.Pro531Thr.

We initially identified four germline EPAS1 variants during validation of NGS testing in a cohort of (de-identified) PPGL cases. Five of six PPGL patients with these EPAS1 variants also had germline SDHB mutations, although this association may have been biased by the fact that our validation cohort deliberately included a predominance of cases with known PPGL-associated mutations. When we extended EPAS1 testing to a larger cohort $(n=300)$ including cases from Australia, Germany, Italy and Poland, we found 15 additional cases with germline EPAS1 variants, five of whom had germline mutations in $S D H$ genes. In the combined cohort, we did not find an association between SDHx mutations and

This work is licensed under a Creative Commons Attribution 4.0 International License. 
EPAS1 variants. Of variants present in gnomAD, only c.581A $>$ G (p.His194Arg), c.2353C >A (p.Pro785Thr) and c. $2365 \mathrm{~A}>\mathrm{G}$ (p.Ile789Val) were more common in PPGL patients than European non-Finnish controls. EPAS1 variant c.739C >A (p.Arg247Ser) is novel and not present in gnomAD.

We found that EPAS1 variants p.Arg247Ser, p.Phe374Tyr and p.Pro785Thr were stable in normoxia in diverse cellular backgrounds (HEK293, PC12 and HeLa cells). These first-line assessments suggested that residues distant from hydroxylation sites in HIF- $2 \alpha$ could also affect its stability. We then tested whether this normoxic stability was due to failure of pVHL recognition. As expected, the known gain-of-function variant p.Pro531Thr did not interact with pVHL in normoxia; of the other variants, only our novel variant p.Arg247Ser also failed to interact with pVHL. Our structural models confirmed that EPAS1/HIF-2 $\alpha$ p.Arg247 directly interacts with pVHL p.Asp143 (salt bridge) and p.Gln145 (hydrogen bond). Interestingly, it has been previously shown that the tumorigenic mutant p.Gln145His of pVHL (Gallou et al. 1999) failed to form a complex with HIF- $2 \alpha$ and target it for degradation (Miller et al. 2005). We expect that our predicted mode of interaction is relevant during the early phase of recognition between pVHL and HIF- $2 \alpha$. Mutating Arg247 by a serine can disrupt the long-range electrostatic attraction of pVHL and guide pVHL to an incorrect final binding position (Shashikala et al. 2019). Interestingly, residue 247 was already described as being part of a transient interaction relevant to the assembly of complex HIF-2 $\alpha$-HIF $\beta /$ ARNT (Scheuermann et al. 2009, Wu et al. 2015).

Surprisingly, despite being stable in normoxia, p.Phe374Tyr and p.Pro785Thr variants retained interaction with p.VHL. It is possible these variants escape pVHL-mediated degradation by disrupting E3 ubiquitin ligase sites through minor torsions generated by change in amino acid residues. An alternate hypothesis is the p.Phe374Tyr variant may disrupt sumoylation at residues 394 and 497 and thereby modify ubiquitination (van Hagen et al. 2010). These possibilities require further investigation.

In transcriptional studies, p.Phe374Tyr and p.Pro785Thr showed similar transactivation of a HIF- $2 \alpha-$ reporter gene compared with the positive control p.Pro531Thr. However, only p.Thr766Pro was able to induce endogenous HIF-2 $\alpha$-responsive CCND1 in a manner comparable to p.Pro531Thr, while none of our HIF- $2 \alpha$ mutants were able to significantly induce SLC2A1 expression compared to the p.Pro531Thr control.
Taken together, these functional studies suggest that germline EPAS1 variants p.Arg247Ser, p.Phe374Tyr and p.Pro785Thr have variable effects on protein stability, pVHL interaction and transcriptional activity that are similar to, but generally more modest, than the pathogenic somatic variant p.Pro531Thr.

Mosaic EPAS1 variants clustered around codon 531 are unequivocally associated with the Zhuang-Pacak syndrome (Favier et al. 2012, Zhuang et al. 2012, Pacak et al. 2013, Yang et al. 2013, Jochmanova \& Lazurova 2014). These same EPAS1 mutations, presumably somatic, are found in up to $10 \%$ of sporadic PPGLs (Buffet et al. 2014, Crona et al. 2014, Comino-Méndez et al. 2013, Yang et al. 2015). Somatic/mosaic EPAS1 mutations have also been described in PPGLs arising on a background of cyanotic congenital heart disease (Vaidya et al. 2018). Conversely, germline EPAS1 variants in the oxygendependent degradation domain (in residues between 533 and 549) were previously identified in subjects with familial erythrocytosis type IV and rarely associated with PPGL alone (Percy et al. 2008). There have been three previous case reports of EPAS1 variant c.1121T>A (p.Phe374Tyr) associated with PPGL. Lorenzo et al. (2013) first reported this germline variant in a 50-year-old man with EPO-dependent polycythemia and metastatic PGL, who at age 35 years had a PGL of the organ of Zuckerkandl resected; structural modeling of c.1121T>A (p.Phe374Tyr) suggested possible interference of HIF- $2 \alpha$ interaction with elongin $\mathrm{C}$ as a mechanism for gain-of-function. Welander et al. (2014) reported the variant in a 56-year-old woman with a benign $50 \mathrm{~mm}$ pheochromocytoma. Taïeb et al. (2016) described this variant in a 63-year-old man with sporadic CNS hemangioblastoma. None of these cases were associated with a family history of pheochromocytoma or paraganglioma.

EPAS1/HIF- $2 \alpha$ expression is higher in tumors associated with VHL or SDHx mutations (Qin et al. 2014), and recent pre-clinical data show HIF-2 $\alpha$ synergizes with $S d h b$ deficiency to promote a metastatic cellular phenotype (Morin et al. 2020). It is possible therefore even mild hypermorphic activity of the germline EPAS1/ HIF- $2 \alpha$ variants described herein, extended over a patient's lifetime, would also synergize with SDH deficiency (or any other pseudohypoxic stimulus) to promote PPGL development. In this regard, it would be most interesting to study PPGLs associated with germline EPAS1 variants for a pseudohypoxic gene expression signature. Whether germline EPAS1 variants we have described here truly modify disease expression when co-inherited with pathogenic variants in PPGL driver genes (in particular,

This work is licensed under a Creative Commons Attribution 4.0 International License. ed from Bioscientifica.com at 04/26/2023 06:41:32AM 
those encoding SDH) will require further clinical studies, and in particular would benefit from large kindred studies where penetrance and disease behavior could be assessed as a function of co-inheritance of the putative modifier allele. Modifier genes for hereditary cancer syndromes have been suspected to explain variable disease penetrance, but few such genes have been identified conclusively (Pinto et al. 2020). At this time, we believe further evidence is needed before recommending screening for germline (as distinct from somatic) EPAS1 variants in PPGL in routine clinical practice, nor would we recommend family screening for these variants. However, these EPAS1 variants may yet be important in pharmacogenomics. Recent research has discovered small molecule inhibitors such as PT2385 and PT2977 that competitively bind to the PAS domain of HIF- $2 \alpha$ and inhibit interaction with HIF- $\beta$, thereby blocking oncogenic transcriptional activities associated with pseudohypoxia (Chen et al. 2016, Cho et al. 2016, Ricketts et al. 2016). Genotyping should be included during clinical trials to determine whether these EPAS1 variants affect response to HIF- $2 \alpha$ antagonist therapies.

The strength of our study is the number of different approaches we have taken to carefully characterize each germline EPAS1 variant, including allele frequency comparison between cases and controls, Bayesian analyses, in silico predictions, structural modeling and functional assessment using six different assays in transfected cells. Our study has several weaknesses: we had very limited clinical information from most subjects, and were not able to examine whether these EPAS1 variants were associated with more aggressive disease or (other than case \#3) with polycythemia; statistical comparison with gnomAD controls is limited by the very low MAF for each variant in our cases and we only used transient transfections for our functional studies, which may have missed more subtle effects on transcriptional induction by some variants and/or effects on cell proliferation. In the absence of significant changes in gene expression, we did not examine protein levels of cyclin D1 or GLUT1 following transfection of these EPAS1 variants. Nevertheless, when taken as a whole, our results argue strongly that these germline EPAS1 variants have at best modest effects on protein function.

In conclusion, germline EPAS1 variants c.739C $>\mathrm{A}$ (p.Arg247Ser), c.1121T $>$ A (p.Phe374Tyr) and c.2353C $>$ A (p.Pro785Thr) share some functional features in common with the known oncogenic somatic variant p.Pro531Thr. These germline variants are unlikely to be pathogenic driver events in isolation. Whether they are co-pathogenic in combination with other events deserves further study, particularly whether they may be additive to other germline variants in $V H L / S D H x$-associated PC/PGL development.

\section{Supplementary materials}

This is linked to the online version of the paper at https://doi.org/10.1530/ ERC-20-0280.

\section{Declaration of interest}

The authors declare that there is no conflict of interest that could be perceived as prejudicing the impartiality of the research reported.

\section{Funding}

This work was supported by NHMRC Project 1108032 to T D, D B and R J C-B and Hillcrest Foundation (Perpetual Trustees) to D B and T D.

\section{Author contribution statement}

T D and R C B conceived the study and wrote the manuscript. R C B, D B, and $T D$ were responsible for curating the genetic test results. Additional oversight of the clinical cohorts was provided by G E, S R, M M, E R, A P, $M P$ and $K P$. Functional studies were performed by $E K$ with supervision by T D, D B and R C B. Structural models were built and analyzed by K B. All authors had full access to the data, and contributed to review of the manuscript.

\section{Acknowledgement}

The authors are grateful to Dr Mercedes Robledo for helpful advice and critical review of the manuscript.

\section{References}

Adzhubei IA, Schmidt S, Peshkin L, Ramensky VE, Gerasimova A, Bork P, Kondrashov AS \& Sunyaev SR 2010 A method and server for predicting damaging missense mutations. Nature Methods 7 248-9. (https://doi.org/10.1038/nmeth0410-248)

Benn DE, Zhu Y, Andrews KA, Wilding M, Duncan EL, Dwight T, Tothill RW, Burgess J, Crook A, Gill AJ, et al. 2018 Bayesian approach to determining penetrance of pathogenic SDH variants. Journal of Medical Genetics 55 729-734. (https://doi.org/10.1136/ jmedgenet-2018-105427)

Berra E, Benizri E, Ginouvès A, Volmat V, Roux D \& Pouysségur J 2003 HIF prolyl-hydroxylase 2 is the key oxygen sensor setting low steady-state levels of HIF-1 $\alpha$ in normoxia. EMBO Journal 22 4082-4090. (https://doi.org/10.1093/emboj/cdg392)

Buffet A, Smati S, Mansuy L, Menara M, Lebras M, Heymann MF, Simian C, Favier J, Murat A, Cariou B, et al. 2014 Mosaicism in HIF2A-related polycythemia-paraganglioma syndrome. Journal of Clinical Endocrinology and Metabolism 99 E369-E373. (https://doi. org/10.1210/jc.2013-2600)

Chen W, Hill H, Christie A, Kim MS, Holloman E, Pavia-Jimenez A, Homayoun F, Ma Y, Patel N, Yell P, et al. 2016 Targeting renal cell carcinoma with a HIF-2 antagonist. Nature 539 112-117. (https:// doi.org/10.1038/nature19796) 
Cho H, Du X, Rizzi JP, Liberzon E, Chakraborty AA, Gao W, Carvo I, Signoretti S, Bruick RK, Josey JA, et al. 2016 On-target efficacy of a HIF-2 $\alpha$ antagonist in preclinical kidney cancer models. Nature 539 107-111. (https://doi.org/10.1038/nature19795)

Comino-Méndez I, de Cubas AA, Bernal C, Álvarez-Escolá C, SánchezMalo C, Ramirez-Tortosa CL, Pedrinaci S, Rapizzi E, Ercolino T, Bernini G, et al. 2013 Tumoral EPAS1 (HIF2A) mutations explain sporadic pheochromocytoma and paraganglioma in the absence of erythrocytosis. Human Molecular Genetics 22 2169-2176. (https://doi. org/10.1093/hmg/ddt069)

Crona J, Nordling M, Maharjan R, Granberg D, Stålberg P, Hellman P \& Björklund P 2014 Integrative genetic characterization and phenotype correlations in pheochromocytoma and paraganglioma tumours. PLOS ONE 9 e86756. (https://doi.org/10.1371/journal. pone.0086756)

Dahia PL, Ross KN, Wright ME, Hayashida CY, Santagata S, Barontini M, Kung AL, Sanso G, Powers JF, Tischler AS, et al. 2005 A HIF1alpha regulatory loop links hypoxia and mitochondrial signals in pheochromocytomas. PLoS Genetics 1 72-80. (https://doi. org/10.1371/journal.pgen.0010008)

Dengler VL, Galbraith MD \& Espinosa JM 2014 Transcriptional regulation by hypoxia inducible factors. Critical Reviews in Biochemistry and Molecular Biology 49 1-15. (https://doi.org/10.3109/1 0409238.2013.838205)

Ding M, Coward RJ, Jeansson M, Kim W \& Quaggin SE 2013 Regulation of hypoxia-inducible factor 2-a is essential for integrity of the glomerular barrier. American Journal of Physiology: Renal Physiology 304 F120-F126. (https://doi.org/10.1152/ ajprenal.00416.2012)

Erbel PJ, Card PB, Karakuzu O, Bruick RK \& Gardner KH 2003 Structural basis for PAS domain heterodimerization in the basic helix-loophelix-PAS transcription factor hypoxia-inducible factor. PNAS $\mathbf{1 0 0}$ 15504-15509. (https://doi.org/10.1073/pnas.2533374100)

Favier J, Buffet A \& Gimenez-Roqueplo AP 2012 HIF2A mutations in paraganglioma with polycythemia. New England Journal of Medicine 367 2161. (https://doi.org/10.1056/NEJMc1211953)

Gallou C, Joly D, Méjean A, Staroz F, Martin N, Tarlet G, Orfanelli MT, Bouvier R, Droz D, Chrétien Y, et al. 1999 Mutations of the VHL gene in sporadic renal cell carcinoma: definition of a risk factor for VHL patients to develop an RCC. Human Mutation 13 464-475. (https://doi.org/10.1002/(SICI)1098-1004(1999)13:6<464::AIDHUMU6>3.0.CO;2-A)

Hon WC, Wilson MI, Harlos K, Claridge TD, Schofield CJ, Pugh CW, Maxwell PH, Ratcliffe PJ, Stuart DI \& Jones EY 2002 Structural basis for the recognition of hydroxyproline in HIF-1 alpha by pVHL. Nature 417 975-978. (https://doi.org/10.1038/nature00767)

Jochmanova I \& Lazurova I 2014 A new twist in neuroendocrine tumor research: Pacak-Zhuang syndrome, HIF-2 $\alpha$ as the major player in its pathogenesis and future therapeutic options. Biomedical Papers 158 175-180. (https://doi.org/10.5507/bp.2014.021)

Kaelin Jr WG, Ratcliffe PJ \& Semenza GL 2016 Pathways for oxygen regulation and homeostasis: the 2016 Albert Lasker Basic Medical Research Award. JAMA 316 1252-1253. (https://doi.org/10.1001/ jama.2016.12386)

Karczewski KJ, Francioli LC, Tiao G, Cummings BB, Alföldi J, Wang Q, Collins RL, Laricchia KM, Ganna A, Birnbaum DP, et al. 2020 The mutational constraint spectrum quantified from variation in 141,456 humans. Nature 581 434-443. (https://doi.org/10.1038/s41586-0202308-7)

Kozakov D, Hall DR, Xia B, Porter KA, Padhorny D, Yueh C, Beglov D \& Vajda S 2017 The ClusPro web server for protein-protein docking. Nature Protocols 12 255-278. (https://doi.org/10.1038/ nprot.2016.169)

Lin Q, Cong X \& Yun Z 2011 Differential hypoxic regulation of hypoxia-inducible factors $1 \alpha$ and $2 \alpha$. Molecular Cancer Research 9 757-765. (https://doi.org/10.1158/1541-7786.MCR-11-0053)
Liu YV, Baek JH, Zhang H, Diez R, Cole RN \& Semenza GL 2007 RACK1 competes with HSP90 for binding to HIF- $1 \alpha$ and is required for O2-independent and HSP90 inhibitor-induced degradation of HIF1 $\alpha$. Molecular Cell 25 207-217. (https://doi.org/10.1016/j. molcel.2007.01.001)

Loboda A, Jozkowicz A \& Dulak J 2010 HIF-1 and HIF-2 transcription factors - similar but not identical. Molecules and Cells 29 435-442. (https://doi.org/10.1007/s10059-010-0067-2)

Lorenzo FR, Yang C, Ng Tang Fui M, Vankayalapati H, Zhuang Z, Huynh T, Grossmann M, Pacak K \& Prchal JT 2013 A Novel EPAS1/ HIF2A germline mutation in a congenital polycythaemia with paraganglioma. Journal of Molecular Medicine 91 507-512. (https:// doi.org/10.1007/s00109-012-0967-z)

Maxwell PH, Wiesener MS, Chang GW, Clifford SC, Vaux EC, Cockman ME, Wykoff CC, Pugh CW, Maher ER \& Ratcliffe PJ 1999 The tumour suppressor protein VHL targets hypoxia-inducible factors for oxygen-dependent proteolysis. Nature 399 271-275. (https://doi.org/10.1038/20459)

Meneses AM \& Wielockx B 2016 PHD2: from hypoxia regulation to disease progression. Hypoxia 4 53-67. (https://doi.org/10.2147/HP. S53576)

Miller F, Kentsis A, Osman R \& Pan ZQ 2005 Inactivation of VHL by tumorigenic mutations that disrupt dynamic coupling of the pVHL. hypoxia-inducible transcription factor-1alpha complex. Journal of Biological Chemistry 280 7985-7996. (https://doi.org/10.1074/jbc. M413160200)

Min JH, Yang H, Ivan M, Gertier F, Kaelin WG Jr \& Pavletich NP 2002 Structure of an HIF-1 $\alpha$-pVHL complex: hydroxyproline recognition in signaling. Science 296 1886-1889. (https://doi.org/10.1126/ science.1073440)

Minikel EV, Vallabh SM, Lek M, Estrada K, Samocha KE, Sathirapongsasuti JF, McLean CY, Tung JY, Yu LP, Gambetti P, et al. 2016 Quantifying prion disease penetrance using large population control cohorts. Science Translational Medicine 8 322ra9. (https://doi. org/10.1126/scitranslmed.aad5169)

Morin A, Goncalves J, Moog S, Castro-Vega LJ, Job S, Buffet A, Fontenille MJ, Woszczyk J, Gimenez-Roqueplo AP, Letouzé E, et al. 2020 TET-mediated hypermethylation primes SDH-deficient cells for HIF2 $\alpha$-driven mesenchymal transition. Cell Reports 30 4551.e7-4566. e7. (https://doi.org/10.1016/j.celrep.2020.03.022)

Pacak K, Jochmanova I, Prodanov T, Yang C, Merino MJ, Fojo T, Prchal JT, Tischler AS, Lechlan RM \& Zhuang Z 2013 New syndrome of paraganglioma and somatostatinoma associated with polycythemia. Journal of Clinical Oncology 31 1690-1698. (https:// doi.org/10.1200/JCO.2012.47.1912)

Percy MJ, Furlow PW, Lucas GS, Li X, Lappin TR, McMullin MF \& Lee FS 2008 A gain-of-function mutation in the HIF2A gene in familial erythrocytosis. New England Journal of Medicine 358 162-168. (https://doi.org/10.1056/NEJMoa073123)

Pinto EM, Figueiredo BC, Chen W, Galvao HCR, Formiga MN, Fragoso MCBV, Ashton-Prolla P, Ribeiro EMSF, Felix G, Costa TEB, et al. $2020 \mathrm{XAF} 1$ as a modifier of p53 function and cancer susceptibility. Science Advances 6 eaba3231. (https://doi.org/10.1126/sciadv.aba3231)

Qin N, de Cubas AA, Garcia-Martin R, Richter S, Peitzch M, Menschikowski M, Lenders JW, Timmers HJ, Mannelli M, Opocher G, et al. 2014 Opposing effects of HIF1 $\alpha$ and HIF $2 \alpha$ on chromaffin cell phenotypic features and tumor cell proliferation: insights from MYC-associated factor X. International Journal of Cancer 135 2054-2064. (https://doi.org/10.1002/ijc.28868)

Ricketts CJ, Crooks DR, Linehan WM 2016 Targeting HIF2 $\alpha$ in clear-cell renal cell carcinoma. Cancer Cell 30 515-517. (https://doi. org/10.1016/j.ccell.2016.09.016)

Robledo M, Currás-Freixes M \& Cascón A 2017 Molecular genetics of pheochromocytoma and paraganglioma. In Diagnostic and Therapeutic Nuclear Medicine for Neuroendocrine Tumors, pp. 15-45. Springer. (https://doi.org/10.1007/978-3-319-46038-3)

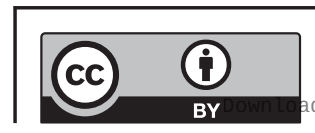

This work is licensed under a Creative Commons Attribution 4.0 International License. 
Ruan K, Song G \& Ouyang G 2009 Role of hypoxia in the hallmarks of human cancer. Journal of Cellular Biochemistry 107 1053-1062. (https://doi.org/10.1002/jcb.22214)

Scheuermann TH, Tomchick DR, Machius M, Guo Y, Bruick RK \& Gardner KH 2009 Artificial ligand binding within the HIF2alpha PAS-B domain of the HIF2 transcription factor. PNAS 106 450-455. (https://doi.org/10.1073/pnas.0808092106)

Schödel J, Oikonomopoulos S, Ragoussis J, Pugh CW, Ratcliffe PJ \& Mole DR 2011 High-resolution genome-wide mapping of HIFbinding sites by ChIP-seq. Blood 117 e207-e217. (https://doi. org/10.1182/blood-2010-10-314427)

Schwarz JM, Cooper DN, Schuelke M \& Seelow D 2014 MutationTaster2: mutation prediction for the deep-sequencing age. Nature Methods 11 361-2. (https://doi.org/10.1038/nmeth.2890)

Shashikala HBM, Chakravorty A \& Alexov E 2019 Modeling electrostatic force in protein-protein recognition. Frontiers in Molecular Biosciences 6 94. (https://doi.org/10.3389/ fmolb.2019.00094)

Taïeb D, Barlier A, Yang C, Pertuit M, Tchoghandjian A, Rochette C, Zattara-Canoni H, Figarella-Branger D, Zhuang Z, Pacak K, et al. 2016 Somatic gain-of-function HIF2A mutations in sporadic central nervous system hemangioblastomas. Journal of Neuro-Oncology 126 473-481. (https://doi.org/10.1007/s11060-015-1983-y)

Tarade D, Robinson CM, Lee JE \& Ohh M 2018 HIF-2 alpha-pVHL complex reveals broad genotype-phenotype correlations in HIF-2 alpha-driven disease. Nature Communications 9 3359-3359. (https:// doi.org/10.1038/s41467-018-05554-1)

Toledo RA, Qin Y, Srikantan S, Morales NP, Li Q, Deng Y, Kim SW, Pereira MA, Toledo SP, Su X, et al. 2013 In vivo and in vitro oncogenic effects of HIF2A mutations in pheochromocytomas and paragangliomas. Endocrine-Related Cancer 20 349-359. (https://doi. org/10.1530/ERC-13-0101)

Vaidya A, Flores SK, Cheng ZM, Nicolas M, Deng Y, Opotowsky AR, Lourenço DM Jr, Barletta JA, Rana HQ, Pereira MA, et al. 2018 EPAS1 mutations and paragangliomas in cyanotic congenital heart disease. New England Journal of Medicine 378 1259-1261. (https://doi. org/10.1056/NEJMc1716652)

van Hagen M, Overmeer RM, Abolvardi SS \& Vertegaal AC 2010 RNF4 and VHL regulate the proteasomal degradation of SUMO-conjugated hypoxia-inducible factor-2 $\alpha$. Nucleic Acids Research 38 1922-1931. (https://doi.org/10.1093/nar/gkp1157)

Vaser R, Adusumalli S, Leng SN, Sikic M \& Ng PC 2016 SIFT missense predictions for genomes. Nature Protocols 11 1-9. (https://doi. org/10.1038/nprot.2015.123)

Warburg O 1956 On respiratory impairment in cancer cells. Science $\mathbf{1 2 4}$ 269-270.

Welander J, Andreasson A, Brauckhoff M, Bäckdahl M, Larsson C, Gimm O \& Söderkvist P 2014 Frequent EPAS1/HIF2 $\alpha$ exons 9 and 12 mutations in non-familial pheochromocytoma. Endocrine-Related Cancer 21 495-504. (https://doi.org/10.1530/ERC-13-0384)

Wu D, Potluri N, Lu J, Kim Y \& Rastinejad F 2015 Structural integration in hypoxia-inducible factors. Nature 524 303-308. (https://doi. org/10.1038/nature14883)

Yang C, Sun MG, Matro J, Huynh TT, Rahimpour S, Prchal JT, Lechan R, Lonser R, Pacak K \& Zhuang Z 2013 Novel HIF2A mutations disrupt oxygen sensing, leading to polycythemia, paragangliomas, and somatostatinomas. Blood 121 2563-2566. (https://doi.org/10.1182/ blood-2012-10-460972)

Yang C, Hong CS, Prchal JT, Balint MT, Pacak K \& Zhuang Z 2015 Somatic mosaicism of EPAS1 mutations in the syndrome of paraganglioma and somatostatinoma associated with polycythemia. Human Genome Variation 2 15053. (https://doi.org/10.1038/ hgv.2015.53)

Zhuang Z, Yang C, Lorenzo F, Merino M, Fojo T, Kebebew E, Popovic V, Stratakis CA, Prchal JT \& Pacak K 2012 Somatic HIF2A gain-offunction mutations in paraganglioma with polycythemia. New England Journal of Medicine 367 922-930. (https://doi.org/10.1056/ NEJMoa1205119)

Received in final form 17 November 2020

Accepted 7 December 2020

Accepted Manuscript published online 11 December 2020
This work is licensed under a Creative Commons Attribution 4.0 International License. 